\title{
TRAUMATIC BRAIN INJURY: EPIDEMIOLOGY, MODE AND TYPE OF INJURY AND MANAGEMENT. A STUDY OF TERTIARY CARE HOSPITAL IN WESTERN INDIA
}

KEY WORDS: Traumatic Head Injury, Mode Of Head Injury, Epidemiology

\section{Dr. Meghna Kinjalk}

Dr. Dilraj Kadlas*

Dr. Pooja Agarwal
M.B.B.S. , Junior Resident, Department Of General Surgery, MGM Medical College And Hospital, Kamothe, Navi Mumbai.

DNB (Neurosurgery), Assistant Professor, Department Of General Surgery, MGM Medical College And Hospital, Kamothe, Navi Mumbai. *Corresponding Author

M.B.B.S. , Junior Resident, Department Of General Surgery, MGM Medical College And Hospital, Kamothe, Navi Mumbai.

The morbidity and quality of life after head injury is long and devastating. The symptoms may persist for lifetime and if not, then can be long enough to affect a person's health/the working conditions and definitely the monetary factor for coping up with this comes into a larger picture. It is also one of the leading causes of lifelong disability or death worldwide. The presentation may vary between a conscious patient on arrival to the emergency room, to a person with seizures, ear bleed or drowsiness. The various types of presentation go hand in hand with different types of head injury, its management, prognosis and long-term impact on a person's life. Despite various studies and appropriate guidelines, the morbidity after head injury remains high. This study has a purpose to correlate various presentations the epidemiology types of head injury and its management options in a tertiary care hospital.

\section{OBJECTIVES:}

a. To study the demographic profile and gender distribution of patients presenting to emergency room in a tertiary care hospital in western India.

b. To study the mode and type of head injury, Imaging finding and its management.

METHODOLOGY: It was a prospective study of consecutive 200 patients presenting to a tertiary care hospital: Mahatma Gandhi Mission's Medical college and hospital, Kamothe, Navi Mumbai. Institute Ethical committee approval was obtained before the start of study. All the age groups was included. There were no exclusion criterias Result was tabulated and analysed at the end of the study.

RESULT: This study enrolled 200 patients in which male were more common than female, young adults more commonly affected. Majority of patients were treated conservatively and improved.

CONCLUSION: The most common cause of traumatic brain injury is road traffic accident and relating it with the most common age group , brings us to the conclusion of importance of safety measures on road amongst young adults. Hence, preventing the wrath of morbidity associated with the debilitating head injury. This also helps in improving the quality of life of the patient and the care giver.

\section{INTRODUCTION:}

One of the devastating emotional, physical and financial burden is traumatic brain injury and it makes the head injury, a major cause of mortality in patients presenting to emergency bay.

For effective management of head injury, it is important to understand the most common presentation and the management of head injury.

\section{METHODOLOGY:}

This study was a prospective study done at Mahatma Gandhi Mission's Medical college and hospital, Kamothe, Navi Mumbai

This hospital is in rural area of Western India. A total of 200 consecutive patients who presented to emergency with head injury were included in this study. Result was analysed by appropriate statistical analysis tests, considering following parameters: Age, Gender, Demographic profile, Glasgow Coma Scale, Mode of Injury, Types of Injury, Imaging findings.

\section{RESULTS:}

Patients admitted to the hospital with traumatic brain injury were 200 . The age group with maximum traumatic brain injury was between 20-30 years. Young adults were in majority. There were majority (147) of males and (43) females. Most common cause was road traffic accident (113) followed by assault (57) and fall from height (20).

The most common head injury was clean incised wound on scalp (130) followed by scalp laceration (29), abrasion on scalp (26), fracture skull (13) and base of skull fracture (2).

Most of the patients had normal brain on CT Scan reporting. Fracture skull was the most common abnormality found on CT scan. Total patients treated conservatively were 126. Majority of patients improved, 12 patients took discharge against medical advice due to need of end of life care or poor prognosis. Mortality was seen in patients with severe head injury on presentation to emergency room.

Table 1 : Age distribution

\begin{tabular}{|l|l|}
\hline Age (in years) & Number of patients presented \\
\hline $0-10$ & 24 \\
\hline $10-20$ & 40 \\
\hline $20-30$ & 62 \\
\hline $30-40$ & 13 \\
\hline $40-50$ & 26 \\
\hline $50-60$ & 6 \\
\hline $60-70$ & 27 \\
\hline $70-80$ & 2 \\
\hline
\end{tabular}

Table 2 : Demographic profile

\begin{tabular}{|l|l|}
\hline Demography & Number of patients presented \\
\hline Urban & 78 \\
\hline Rural & 112 \\
\hline
\end{tabular}

Table 3 : Gender distribution

\begin{tabular}{|l|l|}
\hline Gender & Total number of patients \\
\hline Male & 147 \\
\hline
\end{tabular}

\begin{tabular}{|c|c|c|}
\hline Submitted : $19^{\text {th }}$ July,2019 & Accepted : $21^{\text {th }}$ August,2019 & 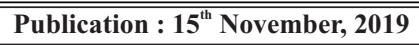 \\
\hline
\end{tabular}




\begin{tabular}{|l|l|}
\hline Female & 43 \\
Table 4 : Mode of head injury \\
\begin{tabular}{|l|l|}
\hline Mode of injury & Total number of patients presented \\
\hline Road traffic accident & 113 \\
\hline Assault & 57 \\
\hline Fall from height & 20 \\
\hline Gun-shot injury & 0 \\
\hline Blast injury & 1 \\
\hline Sports injury & 9 \\
\hline
\end{tabular}
\end{tabular}

\section{Table 5 : Types of head injury}

\begin{tabular}{|l|l|}
\hline Types & Number of patients presented \\
\hline $\begin{array}{l}\text { Clean incised wound on } \\
\text { scalp }\end{array}$ & 130 \\
\hline Scalp laceration & 29 \\
\hline Fracture skull & 13 \\
\hline Base of skull fracture & 2 \\
\hline Abrasions on scalp & 26 \\
\hline
\end{tabular}

\section{Table 6: CT Scan findings}

\begin{tabular}{|l|l|}
\hline CT Scan findings & $\begin{array}{l}\text { Total number of patients } \\
\text { presented }\end{array}$ \\
\hline Cerebral contusion & 22 \\
\hline Fracture : skull & 57 \\
\hline Extra-dural haematoma & 18 \\
\hline Sub-dural haematoma & 13 \\
\hline Subarachnoid haemorrhage & 7 \\
\hline Intracerebral haemorrhage & 4 \\
\hline Normal & 79 \\
\hline
\end{tabular}

Table 7: Management of head injury

\begin{tabular}{|l|l|}
\hline Management & Total number of patients \\
\hline Admission for Observation & 87 \\
\hline Surgical management & 74 \\
\hline Intensive care unit admission & 39 \\
\hline
\end{tabular}

\section{DISCUSSION :}

In the above study males $(73.5 \%)$ were more affected than females (21.5\%). Literature also suggests that most affected gender is male. ${ }^{(1)}$

The most common cause being road traffic accident. Other causes were fall from height, assault, sports injury and blast injury.No gun shot injury was reported.

The need of CT Scan in a patient was assessed by the standard guidelines. Most of the patients reported had a normal CT Scan (brain) finding. The cerebral concussion was considered, on proper history taking and they were admitted for 24 to 48 hours observation.

However, a normal CT scan does not mean that everything is alright as the patient may be suffering from diffuse axonal injury. ${ }^{(2)(3)}$

Few patients who had a normal CT Scan were diagnosed to have diffuse axonal injury and were managed accordingly and had a longer follow up period.

Patients were managed surgically, who had a decrease of Glasgow coma scale by 2 or 3, and other warning signs , during management in Intensive care unit.

Depressed skull fracture, extradural haematoma with volume $>30 \mathrm{cc}$, subdural haematomas with warning signs and severe head injury were invariably managed surgically.

Studies report that new health problems may also arise in patients with head injury along with the aging process. These include a l.5times increased risk of depression ${ }^{(4)}$ and a 2.3 and 4.5 times increased risk of Alzheimer's disease associated with moderate and severe head injury, respectively. ${ }^{(5)}$

"To facilitate recovery, minimize the adverse outcomes of TBI, and promote overall health, timely and appropriate access to both medical care and non medical services are critical. ${ }^{(6) "}$

\section{CONCLUSION :}

At the end of this study on complete analysis, we came to the conclusion that in developed and developing countries, the mode of traumatic head injury remains the same. The point to ponder is that this mode is preventable most of the time. The after life of a patient with head injury should be managed with the same seriousness, as is the patient which is managed in a "red zone" in emergency bay. It forms a major financial and emotional lag on the family and in a larger picture affects the economy and holistic growth of the residential area and society.

\section{REFERENCES :}

1. Engberg A, Teasdale TW. Traumatic brain injury in children in Denmark: $\bar{A}$ national 15-year study.Eur JEpidemiol 1998;14:165-73.

2. Paterakis K, Karantanas AH, Komnos A, Volikas Z Outcome of patients with diffuse axonal injury: the significance and prognostic value of MRI in the acute phase.JTrauma 2000;49:1071-5 16 .

3. Hume AJ, Graham DI, Jennett B. The structural basis of moderate disability after traumatic brain damage. Journal Neurology, Neurosurgery and Psychiatry 2001;71:521-4.

4. Plassman BL, Havlik RJ, Steffens DC, et al. Documented head injury in early adulthood and risk of Alzheimer's disease and other dementias. Neurology. 2000;55(8):1158-1166.

5. Holsinger T, Steffens D C , Phillips C et al. Head injury in early adulthood and the life time risk of depression. Arch Gen Psychiatry. 2002;59(1):17-22.

6. National academy of Sciences, Institute of Medicine and committee on Traumatic Brain Injury .Epidemiology and consequences of traumatic brain injury—an invisible disability. In: Eden J, Stevens R, eds. Evaluating the HRSA Traumatic Brain Injury Program. Washington, DC: National Academies Press; 2006:33-57. 